\title{
CONCEPTUAL DESIGN OF INJECTION MOULD TOOL FOR INLET CHAMBER OF AN AIR INFLATOR
}

\author{
Ashwaghosh.R.S ${ }^{1}$, Hemanth.R ${ }^{1}$ \\ ${ }^{1}$ Dept. of PG studies, Govt. Tool Room \& Training centre, Mysore, Karnataka, India \\ ${ }^{2}$ Dept. of PG studies, Govt. Tool Room \& Training centre, Mysore, Karnataka, India
}

\begin{abstract}
Plastic products can be manufactured by various processes. Injection moulding is one of the techniques used to produce plastic products by forcing the molten plastic material under pressure into a mould, where it is solidified and subsequently released by opening the two halves of the mould. Tool design and development is a specialized and critical area. This paper presents the conceptual design of plastic injection mould tool for inlet chamber of an air inflator, which is used for air filling for the dunnage bags. The material used for the production of the component is ABS (Acrylonitrile-Butadience-Styrene).The technique is incorporated to produce a good quality component considering the ease of manufacturability, assembly and positive ejection of the component with minimum possible time and cost. Designing of mould is carried out by using computer aided designing software Unigraphics. The tool is of two plate, single cavity, stripper plate ejection, cold runner (sprue feed system). Cooling system may not be essential as the component mass is less.
\end{abstract}

Keywords: Key word1, Injection moulding, ABS, split mold, stripper plate ejection.

\section{INTRODUCTION}

Injection moulding is a powerful and comprehensive manufacturing process. However, it can also be a complicated and costly experience. The designer must not only consider part performance requirements, but process and material constraints as well. Effective management of these constraints in a time efficient manner can yield significant product cost savings and a quick time-to-market. Thermoplastics have increasingly replaced conventional materials in a wide range of consumer and industrial products due to their relative strength, ease of manufacturing, and service requirements. Most thermoplastic materials are processed via the injection molding process due to its ability to quickly form complex and precise parts. Material is heated and the subsequent melt is forced into a cavity by hydraulic pressures which may exceed $140 \mathrm{MPa}(20,000 \mathrm{psi})$. Pressure is usually maintained after the initial filling to force additional material into the cavity while the polymer melt cools and solidifies, thereby increasing dimensional stability and part performance. Once the melt has solidified, the mold opens and the part is ejected. The cost of the final molded part is a function of the design, material, and processing expenses. The processing expenses are dependent upon the amortized cost of the injection equipment and may be reduced by either decreasing the cycle time or producing more than one part per cycle using multi-cavity molds. In multi-cavity molds, the polymer melt is forced down a sprue and through a series of branching tubes (runners) to each individual mold cavity. Several parts may then be molded simultaneously with no increase in cycle time (which is dominated by the cooling times). A mold may contain any number of cavities as long as the required clamp tonnage (dependent upon the cavity pressures and projected part areas) does not exceed the maximum clamp tonnage of the injection molding machine. [1]

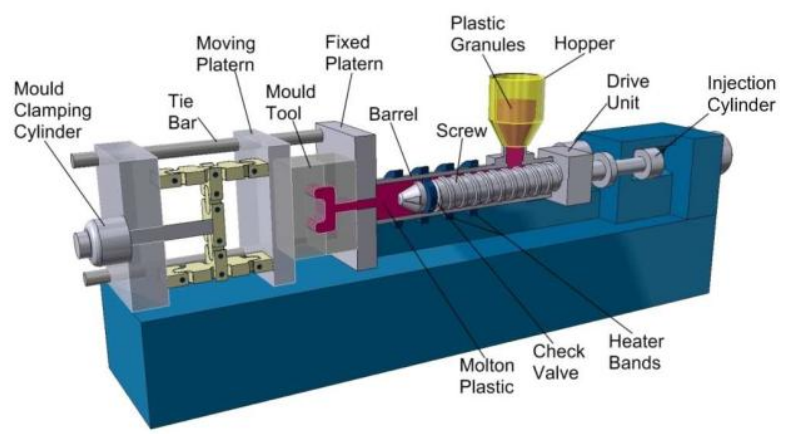

Fig- 1: Injection moulding machine

\subsection{Injection Moulding Cycle}

The injection moulding process stages starts with the feeding of a polymer through hopper to barrel which is then heated with the sufficient temperature to make it flow, then the molten plastic which was melted will be injected under high pressure into the mould the process is commonly known as Injection, After injection pressure will be applied to both platens of the injection moulding machine in order to hold the mould tool together afterwards the product is set to cool which helps it in the solidification process. After the product gets its shape the two platens will move away from each other in order 
to separate the mould tool which is known as mould opening and finally the moulded product is ejected or removed from the mould. And the process will repeat itself. [2]

The moulding cycle starts with the retraction of the ejector plate, followed by closing of the mould. The injection unit melts the polymer resin and injects the polymer melt into the mould. The ram fed injection moulding machine uses a hydraulically operated plunger to push the plastic through a heated region. The melt converges at a nozzle and is injected into the mould. The melt is forced into the mould in two or three stages:

\section{- $\quad$ Stage 1: Fill stage}

During this stage, the mould cavities are filled with molten resin. As the material is forced forward, it passes over a spreader, or torpedo, within the barrel, which causes mixing. This stage is determined by an injection velocity, a pressure, and a time. Injection velocity is the rate at which the plunger moves forward.

\section{- $\quad$ Stage 2: Pack stage}

As the melt enters the mould, it cools and introduces shrinkage. The pack stage is necessary to force more melt into the mould to compensate for shrinkage.

\section{- $\quad$ Stage 3: Hold stage}

When no more material can be forced into the mould, melt can still leak back through the gate. The hold stage applies forces against the material in the cavity until the gate freezes to prevent leaking of the melt.

In some machines, pack and hold are combined into a single second or holding stage. [3], [4]

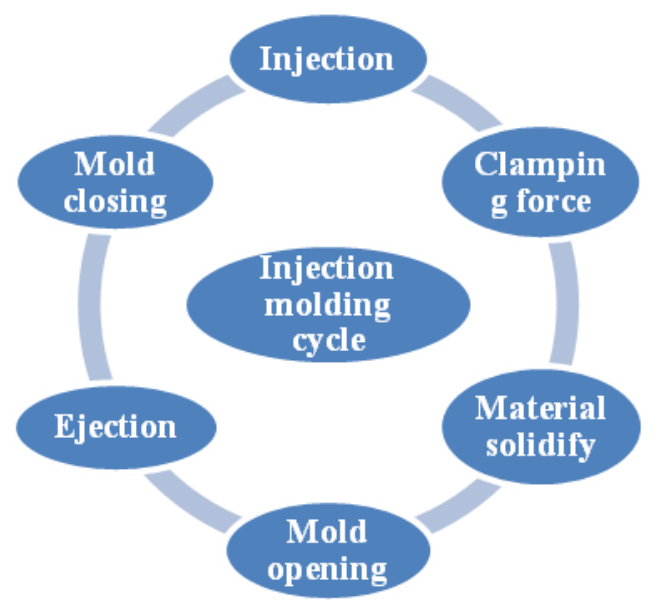

Fig- 2: Injection moulding cycle

The cycle consist of

- Mould close and clamp, (few seconds depends on machine speeds)
- Injection Fill (speed) phase, (few seconds)

- Switchover and Pack (pressure)phase,(few seconds)

- Cooling time (40 to $60 \%$ of cycle time)

Moldflow is the one of developer's software solutions that enhances the design, analysis, and manufacture of injection moulded plastic parts. The commercial success of each of these products often relies heavily upon reducing the time to bring new products to market, reducing engineering and manufacturing costs, and improving product quality and design.

The Moldflow software is useful in all aspects of the injection moulded plastic parts manufacturing process, including part designers, mould designers, manufacturing engineers and machine operators. It enables to speed products to market, decrease manufacturing costs and reduce costly design and manufacturing errors by:

- Assisting part designers in the selection of a plastic material,

- Determining the strength, rigidity and ease of manufacturing of a given part design,

- Predicting the amount a plastic part will shrink or warp during production,

- Optimizing production conditions such as machine temperatures, injection speeds, cooling times and the locations in a mould to inject the plastic.

- Identifying and providing optimized solutions for adverse variations during production,

- Providing features which facilitate collaboration over shared media, such as the internet.

\subsection{Basic Design of Injection Mold Tool}

Various design considerations had been applied in the design. The mold is designed based on the platen dimension of the plastic injection machine used. There is a limitation of the machine, which is the maximum area of machine platen is given by the distance between two tie bars. Therefore, the maximum width of the mould plate should not exceed this distance.

Factors to be considered during designing of injection moulding tool

- Design and material of components

- Number of components required

- Selection of Injection moulding machine

- Number of cavities

- Type of tool

- Selection of parting line

- Positioning of core and cavity

- Ejection system

- Designing of layout

- Fool proofing arrangements

- Cooling elements

- Tool life 


\subsection{Concept of Two-Plate Mold}

This kind of mold is used for parts that are typically gated on or around their edge. It consists of fixed and moving half. The cavity and core can be mounted on the either half, depending upon the part design and location of knock out pin. This mold adapted easily for different design and all parts ejection method.

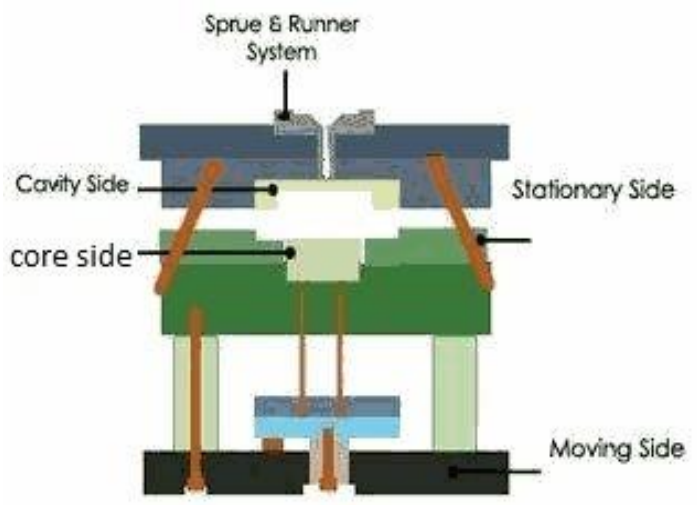

Sider Mold

Fig- 3: Two Plate Mold

\subsection{Concept of Split Mold}

A type of mould consisting of upper and lower half that are compressed together to form a single part.

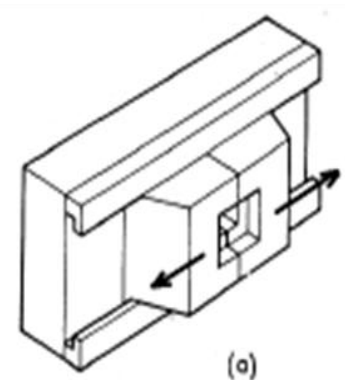

(0)

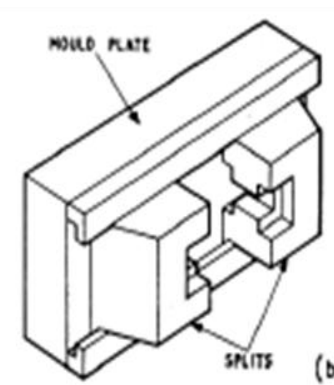

(b)
Fig- 4: Basic split mold. Splits shown in Closed (a) and Open (b) positions

- Split moulds are used where there is a significant amount of undercut detail.

- In such cases it is easier to split the mould cavity completely.

- In the case of a split mould the entire cavity separates in order to eject the component.

- This can be achieved using angled guide pins to move the cavity halves sideways as the mould opens.[5]

\section{METHODOLOGY}

Component is modeled using the software Unigraphics 8.0. The attempt to design a mold tool which can be manufactured $\&$ the other details of the model is shown below.

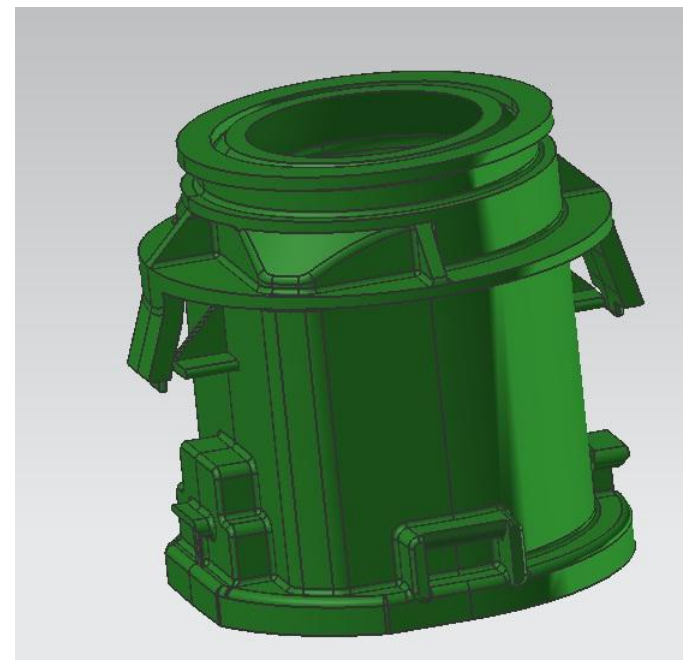

Fig-5: Component model

For the above component (Inlet Chamber) ABS (Acrylonitrile, Butadiene \& Styrene) is used for the production of the component. $\mathrm{ABS}$ is light weight \& ability to be injection molded.

Properties of ABS are:

Specific gravity $-1.08 \times 10^{3} \mathrm{~kg} / \mathrm{m}^{3}$

Melt Temperature $-240^{\circ} \mathrm{C}$

Mould Temperature $-30^{\circ}-80^{\circ} \mathrm{C}$

Apparent Density $-0.45 \mathrm{~g} / \mathrm{cm}^{3}[6]$

Projected area of component: $15.2072 \mathrm{~cm} 2$ (From CAD model).

The following are some commonly used design elements in the above shown component:

- Ribs

- Undercuts

- Unequal wall thickness.

\subsection{Core and Cavity}

Molds separate into two halves called the core and the cavity as shown in Fig $6 \& 7$ to permit the part to be extracted. In general the shape of a part must not cause it to be locked into the mold. 


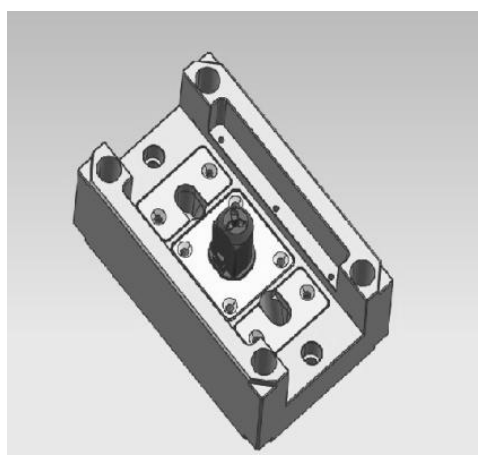

Fig-6: Core

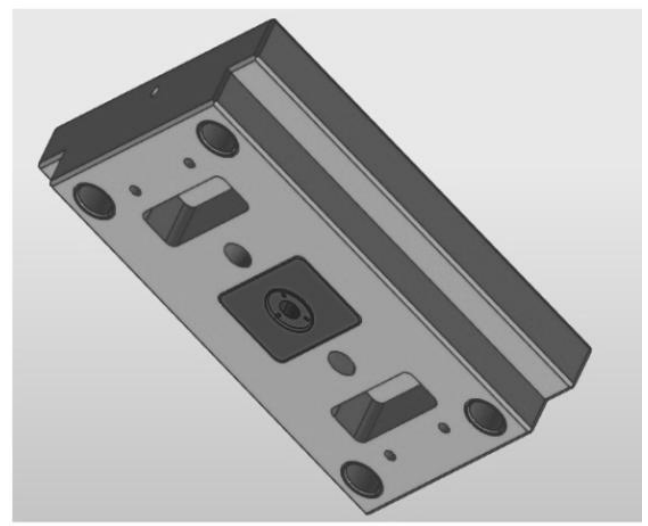

Fig-7: Cavity

\subsection{Feed System}

\subsubsection{Sprue (For cold runner tool)}

The sprue should be tapered $3-5^{0}$ inclusive angle in order to be pulled out of the tool easily. The diameter at the narrow end should be larger than the machine cylinder nozzle opening. As stripper plate ejection is employed Undercut pin type is used.

\subsubsection{Spoke Gate}

Spoke gate is used for cylindrical parts and it is of easy degating and material savings. Disadvantages are the possibility of weld lines and the fact that perfect roundness is unlikely. Typical gate size ranges from 0.8 to $5 \mathrm{~mm}$ diameter. [7]

Spoke or Spider gate is used for circular kind of parts for easy flow of material.

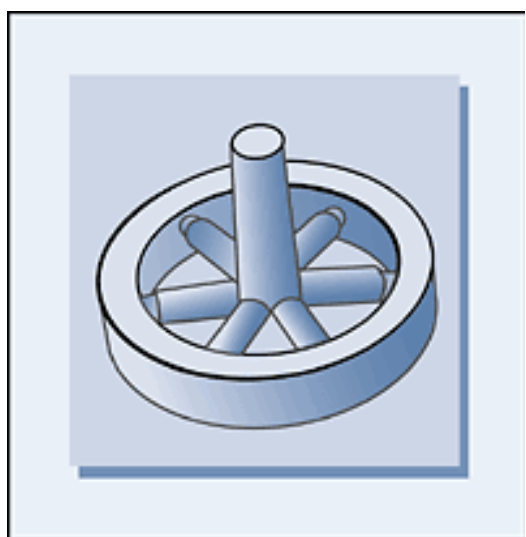

Fig- 8: Spoke Gate

\subsection{Ejection System}

An ejection system is needed to eject the molded part from the cavity at the end of the molding cycle. On cooling the moulded component will shrink onto and remain on the core or moving half when the mould opens.

This comprises of a:

- Hydraulic actuator

- Ejector plate

- Ejector pins

Here stripper plate ejection has been employed by going through the component design.

\subsubsection{Stripper Plate Ejection}

Stripper plate systems are very effective and usually more efficient than pins wherever they can be used as they support the maximum area possible during ejection. These moulds remove the component from the core by moving an entire mould plate to strip the part from the core. Typical applications are for tubular parts and circular, square or rectangular boxes. [8]
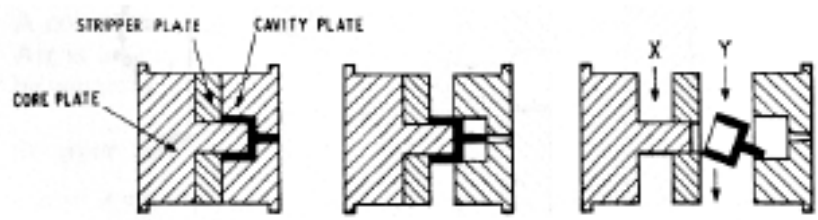

Fig- 9: Stripper Plate Ejection system

\section{CONCLUSIONS}

The work, deals with the Concept of designing an injection mould tool for an Air Inflator. The Split mould design and stripper plate ejection will make it possible to produce high quality product at minimum cost. By proper supply of heat and temperature will overcome the effects on the part being 
produced. The final product is produced with less number of defects.

\section{REFERENCES}

[1]. Kurt A. Beiter, James M. Cardinal, Kos Ishii "Design For Injection Moulding: Balancing Mechanical Requirements, Manufacturing Costs, And Material Selection" [2]. Branislav DULEBA - František GREŠKOVIČ "Materials for Injection Molds Production"

[3]. Jagannatha Rao M B, Dr. Ramni "analysis of plastic flow in two plate multi cavity injection mould for plastic component for pump seal"

[4]. Vishnuvarthanan, M., Rajesh Panda, Ilangovan, S. and Nayak, S.K "Optimization of Injection Molding Cycle Time Using Moldflow Analysis"

[5]. Mould design slides by S.Dalton.

[6]. B. Duleba1*, F. Greškovic2 "Application of Ca Systems at Design and Simulation of Plastic Molded Parts" Specification of ABS material by Eurapipe ABS typical properties generic ABS http://plastics.id.eas.com/generics/1/c/t/acrylonitrilebutadiene-styrene-abs-properties-processing [7]. Design and Manufacturing of Plastic Injection mold by Dr. Mikó Balázs.

[8]. The Mould Design Guide by Peter Zones. 